\title{
A global analysis of subsidence, relative sea-level change and coastal flood exposure
}

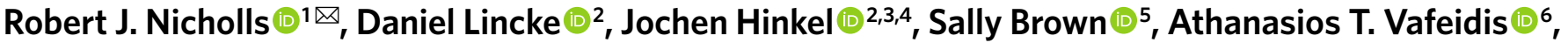 \\ Benoit Meyssignac $\mathbb{D}^{7}$, Susan E. Hanson ${ }^{\mathbb{8}}{ }^{8}$, Jan-Ludolf Merkens ${ }^{6}$ and Jiayi Fang ${ }^{9} 9$
}

\begin{abstract}
Climate-induced sea-level rise and vertical land movements, including natural and human-induced subsidence in sedimentary coastal lowlands, combine to change relative sea levels around the world's coasts. Although this affects local rates of sea-level rise, assessments of the coastal impacts of subsidence are lacking on a global scale. Here, we quantify global-mean relative sea-level rise to be $2.5 \mathrm{~mm} \mathrm{yr}^{-1}$ over the past two decades. However, as coastal inhabitants are preferentially located in subsiding locations, they experience an average relative sea-level rise up to four times faster at 7.8 to $9.9 \mathrm{~mm} \mathrm{yr}^{-1}$. These results indicate that the impacts and adaptation needs are much higher than reported global sea-level rise measurements suggest. In particular, human-induced subsidence in and surrounding coastal cities can be rapidly reduced with appropriate policy for groundwater utilization and drainage. Such policy would offer substantial and rapid benefits to reduce growth of coastal flood exposure due to relative sea-level rise.
\end{abstract}

$\mathrm{t}$ is widely recognized that climate-induced sea-level rise (SLR) is raising water levels around the world's coasts ${ }^{1-3}$ and that this will lead to an increase in flood risk and other impacts unless there is corresponding adaptation ${ }^{4}$. Against this background, a large literature has assessed the magnitude of SLR and its impacts and adaptation needs at global scales ${ }^{2}$. Indeed, this literature is essential for setting and evaluating mitigation targets, strategic adaptation and designing financial arrangements for funding adaptation and compensation for loss and damage. Over time, this literature has progressed from focusing on climate-induced regional SLR to also including geologic sources of local relative sea-level change such as glacial-isostatic adjustment (GIA) to serve local adaptation needs, for which the source of relative SLR is irrelevant. Previous global studies have not quantitatively considered the contribution of subsidence to global SLR risk, which may constitute a serious limitation in global exposure estimates as human-induced subsidence in particular can lead to rates of local SLR that are much higher than current rates of climate-induced SLR. Furthermore, these high rates occur specifically in densely populated areas such as cities and deltas. This could have a large effect on people's experience of relative SLR, but so far the size of this effect has not been studied at global scales.

Important geologic processes that are contributing to relative sea-level change include tectonics, GIA, and subsidence in geologically recent sedimentary deposits such as deltas, which can be substantially enhanced by human agency, especially groundwater withdrawal ${ }^{5-10}$. As global models are available (for example, ref. ${ }^{11}$ ) and it is a long-term stable process causing either uplift or subsidence depending on location, GIA is often considered in global analyses of relative sea level and impacts. Other sources of land-elevation change are not regularly included, being implicitly seen as a local problem.
Natural subsidence, mainly due to the compaction of young sediments in deltas, is widespread and noteworthy ${ }^{12}$. However, the most rapid rates of subsidence are human-induced. These are caused by accelerated compaction primarily due to withdrawal of underground fluids including groundwater, oil and gas, as well as drainage of organic soils ${ }^{8,12}$. As Ericson et al. ${ }^{13}$, Syvitski et al. ${ }^{14}$ and Tessler et al. ${ }^{15}$, among others, have demonstrated, these processes are marked in many of the world's deltas and are often compounded by both local flood defences within the delta and upstream dams, which collectively reduce the sediment supply that maintains these sedimentary landforms. Sand extraction and mining can exacerbate this loss of sediment supply. Cumulatively, human effects on subsidence are at their largest in some coastal cities located on deltas and alluvial plains: a net subsidence of more than $4 \mathrm{~m}$ has occurred during the twentieth century in parts of Tokyo, and 2 to $3 \mathrm{~m}$ in Shanghai, Bangkok, Jakarta and New Orleans ${ }^{16-19}$. Many deltas and subsiding cities are in Asia, and the World Bank ${ }^{20}$ has recognized that subsidence could be as influential as climate-induced SLR in parts of coastal Asia over the twenty-first century.

To analyse the relative importance of subsidence on relative SLR, we consider data for four components of relative sea-level change: (1) climate-induced sea-level change ${ }^{21,22},(2)$ GIA $^{11},(3)$ recent estimates of total deltaic subsidence, including natural and human-induced changes and (4) recent estimates of human-induced subsidence in coastal cities on deltas and alluvial plains (which operate at a sub-delta scale and hence are in addition to the subsidence due to component (3)). In addition to the individual components, we also consider the combined effect of all these components, which is the local relative SLR. To compute global relative SLR, we weight local relative SLR values by the length of coast and thus obtain an estimate of the average relative SLR per kilometre of coast. Given that the distribution of coastal population (and hence SLR risks and

\footnotetext{
'Tyndall Centre for Climate Change Research, University of East Anglia (UEA), Norwich, UK. ${ }^{2}$ Global Climate Forum, Berlin, Germany. ${ }^{3}$ Division of Resource Economics, Thaer-Institute of Agricultural and Horticultural Sciences, Faculty of Life Sciences, Humboldt-University, Berlin, Germany. ${ }^{4}$ Berlin Workshop in Institutional Analysis of Social-Ecological Systems (WINS), Humboldt-University, Berlin, Germany. ${ }^{5}$ Department of Life and Environmental Sciences, Faculty of Science and Technology, Bournemouth University, Bournemouth, UK. ${ }^{6}$ Kiel University, Department of Geography, Kiel, Germany. ${ }^{7}$ LEGOS, Université de Toulouse, CNES, CNRS, UPS, IRD, Toulouse, France. ${ }^{8}$ School of Engineering, University of Southampton, Southampton, UK. ${ }^{9}$ School of

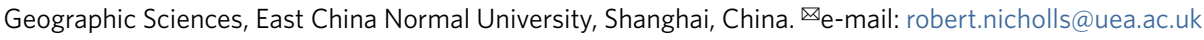




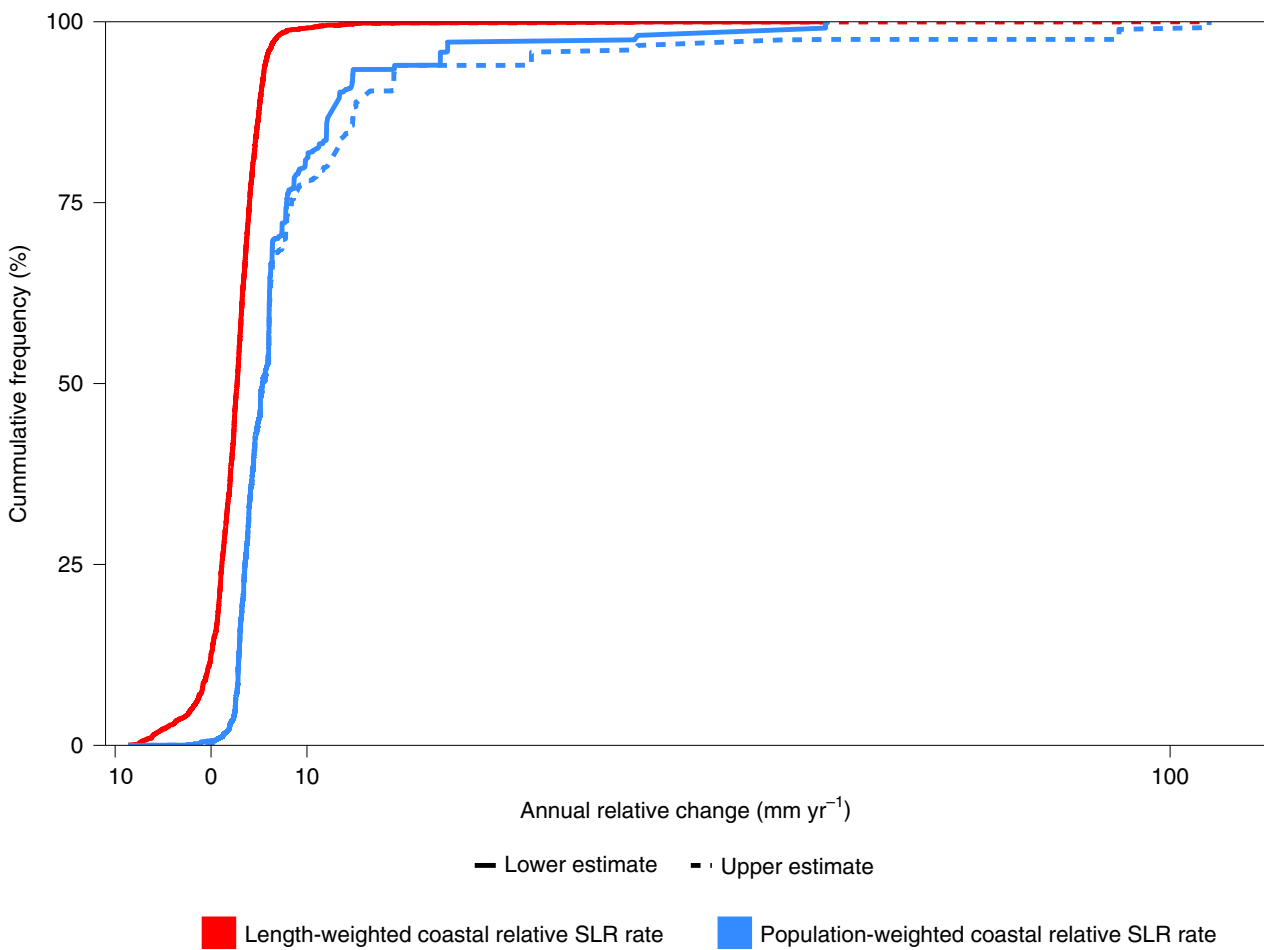

Fig. 1 | Cumulative distribution of contemporary length-weighted and population-weighted coastal relative SLR rates. This includes lower and upper estimates to express uncertainty, although for length weighting the difference is too small to be seen.

adaptation needs) is not uniform, we also estimate the global relative SLR weighted by coastal population, giving an estimate of the average relative SLR per coastal resident. We then consider the relative role of subsidence in enhancing coastal flood risk to 2050 compared with other changes, assuming current estimates of subsidence continue. For this, we focus on the coastal floodplain population (that is, exposure) as a metric as it is independent of adaptation. All components, data and methods are defined and described in more detail in the Methods.

Considering weighting by coastal length, the analysis shows that the contemporary global-mean coastal relative SLR rate, including climate and geologic components, averages $2.5 \mathrm{~mm} \mathrm{yr}^{-1}$ over the past two decades with climate-induced SLR being the dominant component (Fig. 1 and Table 1). This is less than the climate-induced-change component alone as GIA causes a net average fall in relative sea level around the world's coasts. Globally, the combined effect of subsidence components in deltas and coastal cities is almost negligible and cannot be distinguished in the cumulative distribution curve (Extended Data Fig. 1). This reflects that, based on the data analysed, only $6.5 \%$ and $0.8 \%$ of the world's coasts comprise subsiding deltas and subsiding cities, respectively.

In contrast, weighting by coastal population shows that coastal inhabitants on average experienced much higher relative SLR rates, reflecting the heterogeneous distribution of coastal population (Fig. 1 and Table 1). The median relative SLR rate per person is about $5 \mathrm{~mm} \mathrm{yr}^{-1}$, while the mean is up to four times higher at 7.8 to $9.9 \mathrm{~mm} \mathrm{yr}^{-1}$ over the past two decades. This global enhancement of average SLR rate per person mainly reflects that coastal residents are concentrated in subsiding areas, including deltas, and especially in subsiding coastal cities, which gives a high end tail to the distribution (Fig. 1 and Extended Data Fig. 1). Effectively, delta and city subsidence and population density are not independent; higher population densities lead to human actions that promote subsidence and loss of elevation. Furthermore, deltas have fertile soils and have historically been hot spots for human management and
Table 1 | Contribution of the climate and geologic components to relative sea-level change for length-weighted and population-weighted cases, respectively

Relative SLR component

Contribution to relative sea-level change

\begin{tabular}{|c|c|c|c|c|}
\hline & \multicolumn{2}{|c|}{$\begin{array}{l}\text { Coastal-length } \\
\text { weighted }\end{array}$} & \multicolumn{2}{|c|}{$\begin{array}{l}\text { Coastal-population } \\
\text { weighted }\end{array}$} \\
\hline & $\mathrm{mm} \mathrm{yr}^{-1}$ & $\%$ & $\mathrm{~mm} \mathrm{yr}^{-1}$ & $\%$ \\
\hline $\begin{array}{l}\text { Climate-induced SLR } \\
\text { (1993 to 2015) }\end{array}$ & 3.2 & 122 & 3.8 & $\begin{array}{l}39 \text { to } \\
49\end{array}$ \\
\hline GIA & -0.8 & -32 & -0.3 & -3 \\
\hline Delta subsidence & 0.1 & 4 & 1.6 & $\begin{array}{l}16 \text { to } \\
21\end{array}$ \\
\hline City subsidence & 0.1 & 3 & 2.7 to 4.8 & $\begin{array}{l}35 \text { to } \\
49\end{array}$ \\
\hline Global-mean sum & 2.6 & & 7.8 to 9.9 & \\
\hline
\end{tabular}

Average values are reported, except for cities and the global-mean sum where a low/high range is used to express the uncertainty in subsidence (Supplementary Table 2).

development ${ }^{14}$. Hence, the relative sea-level change components linked to human activities tend to increase with population density around the world's coasts (Extended Data Fig. 2). We estimate that $51-70 \%$ of the total global-average relative SLR experienced by people is due to delta and city subsidence (Table 1). In contrast, the global effect of GIA is almost negligible when considering population weighting (Extended Data Fig. 1).

Globally, average sea-level changes over the past two decades are distributed unevenly across coastal length and coastal population (Fig. 1). About $12.5 \%$ of the world's coasts by length are experiencing relative sea-level fall, attributed to uplift caused by GIA. However, these areas only have 2.7 million inhabitants (less than $1 \%$ of global 

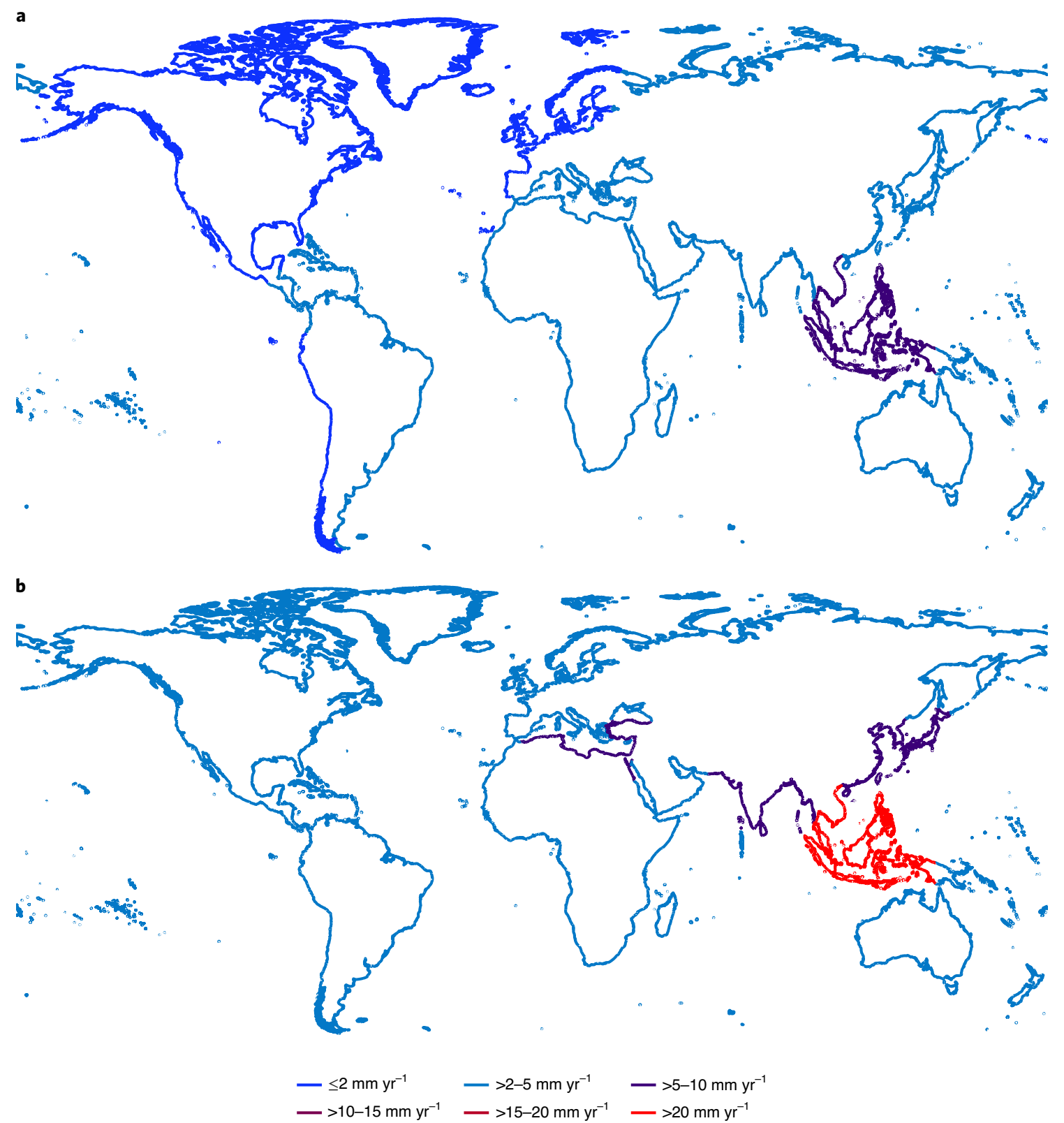

Fig. 2 | Average relative SLR rate for 23 coastal world regions. a,b, Length-weighted (a) and population-weighted (b) average relative SLR rate (Supplementary Table 3 details the region definitions).

coastal population). Conversely, only about $0.7-0.8 \%$ of the world's coasts by length are experiencing a SLR rate above $10 \mathrm{~mm} \mathrm{yr}^{-1}$ (the range covers uncertainty in city subsidence). However, these coasts contain large subsiding cities such as Jakarta and 147-171 million inhabitants (19.1-22.3\% of the global coastal population).

Average coastal-population-weighted relative SLR rate is also often higher at the regional level than coastal-length-weighted relative SLR rate estimates (Fig. 2): 11 of 23 world regions show more than $50 \%$ increases in population-weighted relative SLR rate when compared with coastal-length-weighted relative SLR rate (Supplementary Table 4). Seven regions have an increase of more than 100\% (the Baltic Sea coast, North and West Europe, North American Atlantic coast, North American Pacific coast, South American Pacific coast, southern Mediterranean and Southeast Asia), reflecting regions where coastal residents are strongly concentrated in areas where relative SLR rate is higher. In absolute terms, the effect in South, Southeast and East Asia is noteworthy
(Supplementary Table 4), as these regions collectively contain $71 \%$ of the global coastal population below $10 \mathrm{~m}$ in elevation (546 million out of 768 million people globally in 2015) and $75 \%$ of the global coastal floodplain population (185 million out of 249 million people globally in 2015).

Finally, we assess the contributions of climate-induced SLR, GIA, delta subsidence and city subsidence to the evolution of the global population living in the coastal floodplain from 2015 to 2050 (Fig. 3 ). This assumes that the observed subsidence in deltas and cities continues to 2050 , representing a plausible scenario of future subsidence. In 2015, this floodplain population is approximately 235 million people. Assuming no subsidence and no climate-induced SLR, this population rises to about 280 million people by 2050 due to socioeconomic development alone (here, Shared Socioeconomic Pathway 2 (SSP2) $)^{23}$. Adding the GIA component reduces this number to 270 million, while adding the delta-subsidence component increases it back to about 280 million people. Adding the uncontrolled 


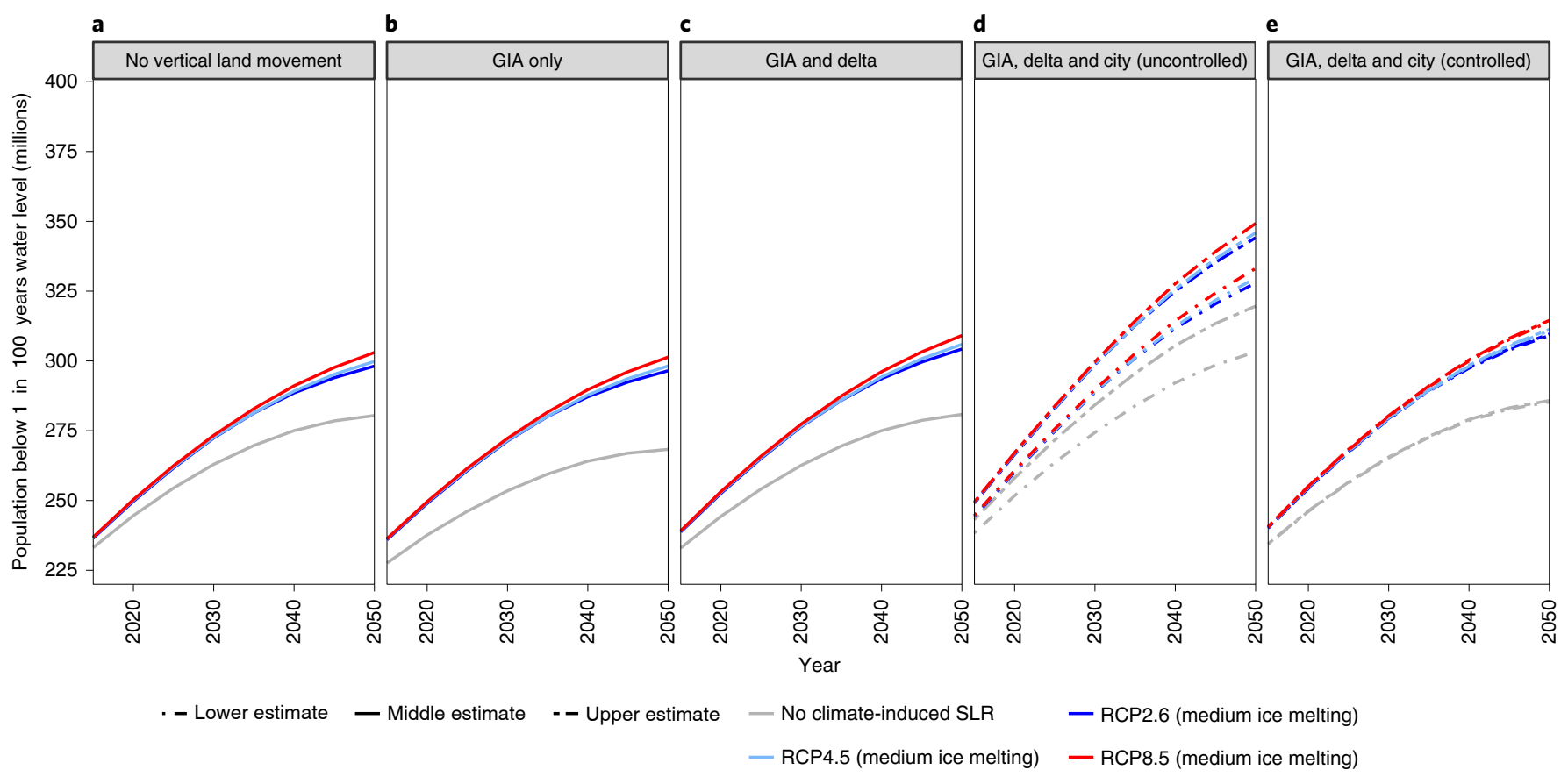

Fig. 3 | Global population in the coastal floodplain from 2015 to 2050. This considers SLR scenarios under RCP2.6, RCP4.5 and RCP8.5 emissions, as well as no climate-induced SLR as a reference, and assumes the SSP2 socioeconomic scenario. Subsidence and GIA assumptions are as indicated. a, No vertical land movement. b, GIA only. c, GIA and delta subsidence. d, GIA, delta and uncontrolled city subsidence. e, GIA, delta and city subsidence controlled to $5 \mathrm{~mm} \mathrm{yr}^{-1}$. The ranges based on lower, middle and upper population estimates shown in $\mathbf{d}, \mathbf{e}$ reflect uncertainty in rates of city subsidence (Fig. 1). Simulations start in 1995 and the floodplain is defined based on the 100-year event.

city-subsidence component further increases the floodplain population to about 305-320 million people (a net increase of 25 to 40 million people summing across the GIA, delta- and city-subsidence components). Additionally, considering climate-induced SLR, the exposed population increases to 330-350 million by 2050 (a net increase of 25 to 30 million people due to climate change; Fig. $3 \mathrm{~d}$ ). The effects of subsidence and climate-induced SLR on exposed population numbers can therefore be seen as being comparable in magnitude over the next 30 years. Under other SSPs, the results are similar (Extended Data Fig. 3).

These findings have important implications for coastal management, climate action and sustainability goals. For climate mitigation, they mean that contemporary and future global SLR risks and adaptation needs are much higher than previously assessed. For adaptation, this means that reducing human-induced subsidence constitutes a globally relevant coastal adaptation option. While from a conceptual point of view it can be debated if managing subsidence constitutes adaptation, from a practical point of view this has a higher potential for reducing coastal exposure than climate mitigation over the next 30 years. For example, if we reduce coastal city subsidence to $5 \mathrm{~mm} \mathrm{yr}^{-1}$, population exposure could be reduced by about $20-35$ million people or $6-10 \%$ by 2050 compared with unreduced city subsidence (Fig. 3e compared with Fig. 3d), whereas under ambitious climate mitigation (that is, from representative concentration pathway (RCP) 8.5 to RCP2.6), population exposure would be reduced by about 5 million people or $1.5 \%$ over the same timeframe. Climate mitigation would lead to much larger benefits after 2050 (refs. ${ }^{2,24}$; not assessed here), and these two policies can, and should, be complementary. Reducing city subsidence to $5 \mathrm{~mm} \mathrm{yr}^{-1}$ or less is feasible as demonstrated in the Netherlands and many Asian cities (for example, Tokyo, Osaka and Shanghai), where it involves managing groundwater withdrawal and maintaining high water tables. However, these policies generally reduce rather than stop all subsidence, $c^{9,17}$ and there are wider implications and risks associated with rising water tables for cities. Therefore, while some subsidence control may be feasible, other SLR adaptation approaches will still be necessary and compatible with adapting to climate change ${ }^{2,18}$. Controlled flooding and sedimentation could be an innovative response to loss of elevation on deltas, especially in agricultural areas. This would involve a major shift in thinking in delta management to controlling rather than eliminating flooding, and recognizing sediment and sedimentation as a resource ${ }^{14,25,26}$.

The influence of subsidence on relative SLR has grown over the twentieth century alongside expanding coastal populations in susceptible areas, notably on deltas and especially in large and expanding cities on those deltas. The results discussed here indicate this will certainly continue and maybe even grow in magnitude and extent with increasing coastal urbanization in susceptible settings. Improved measurements of natural and human-induced subsidence processes are emerging, and analysed systematically as shown here will allow fuller appreciation of the potential consequences of relative SLR at regional to global scales and appropriate responses developed ${ }^{27-29}$.

In conclusion, this Article shows that, due to its coincidence with major population centres, subsidence has global social and economic implications. Its influence on exposure to coastal flooding is comparable to, if not greater than, climate-induced SLR over the next few decades and will remain important thereafter. As such, subsidence should be better recognized in regional and global assessments of relative SLR impacts, and not simply restricted to local assessments. This, in turn, would improve the evidential basis for adaptation, disaster risk reduction, and development strategies in coastal areas.

\section{Online content}

Any methods, additional references, Nature Research reporting summaries, source data, extended data, supplementary information, 
acknowledgements, peer review information; details of author contributions and competing interests; and statements of data and code availability are available at https://doi.org/10.1038/s41558021-00993-z.

Received: 20 April 2020; Accepted: 21 January 2021; Published online: 08 March 202

\section{References}

1. Nerem, R. S. et al. Climate-change-driven accelerated sea-level rise detected in the altimeter era. Proc. Natl Acad. Sci. USA 115, 2022-2025 (2018).

2. Oppenheimer, M. et al. in Special Report on the Ocean and Cryosphere in a Changing Climate (eds Pörtner, H. O. et al.) Ch. 4 (IPCC, Cambridge Univ. Press, 2019).

3. Church, J. A. et al. in Climate Change 2013: The Physical Science Basis (eds Stocker, T. F. et al.) Ch. 13 (IPCC, Cambridge Univ. Press, 2013).

4. Wong, P. P. et al. in Climate Change 2014: Impacts, Adaptation, and Vulnerability (eds Field, C. B. et al.) Ch. 5 (IPCC, Cambridge Univ. Press, 2014).

5. Emery, K. O. \& Aubrey, D. G. Sea Levels, Land Levels, and Tide Gauges (Springer-Verlag, 1991).

6. Rovere, A., Stocchi, P. \& Vacchi, M. Eustatic and relative sea level changes Curr. Clim. Change Rep. 2, 221-231 (2016).

7. Lickley, M. J., Hay, C. C., Tamisiea, M. E. \& Mitrovica, J. X. Bias in estimates of global mean sea level change inferred from satellite altimetry. J. Clim. 31, 5263-5271 (2018).

8. Milliman, J. \& Haq, B. U. (eds) Sea-Level Rise and Coastal Subsidence: Causes, Consequences, and Strategies (Springer, 1996).

9. Erkens, G., Bucx, T., Dam, R., de Lange, G. \& Lambert, J. Sinking coastal cities. Proc. Int. Assoc. Hydrol. Sci. 372, 189-198 (2015).

10. Frederikse, T., Riva, R. E. M. \& King, M. A. Ocean bottom deformation due to present-day mass redistribution and its impact on sea level observations. Geophys. Res. Lett. 44, 12306-12314 (2017).

11. Peltier, W. R., Argus, D. F. \& Drummond, R. Space geodesy constrains ice age terminal deglaciation: the global ICE-6G_C (VM5a) model. J. Geophys. Res. Solid Earth 120, 450-487 (2015)

12. Syvitski, J. P. M. Deltas at risk. Sustain. Sci. 3, 23-32 (2008).

13. Ericson, J. P., Vörösmarty, C. J., Dingman, S. L., Ward, L. G. \& Meybeck, M. Effective sea-level rise and deltas: causes of change and human dimension implications. Glob. Planet. Change 50, 63-82 (2006).

14. Syvitski, J. P. M. et al. Sinking deltas due to human activities. Nat. Geosci. 2, 681-686 (2009).
15. Tessler, Z. D., Vörösmarty, C. J., Overeem, I. \& Syvitski, J. P. M. A model of water and sediment balance as determinants of relative sea level rise in contemporary and future deltas. Geomorphology 305, 209-220 (2018)

16. Nicholls, R. J. Coastal megacities and climate change. GeoJournal 37, 369-379 (1995)

17. Kaneko, S. \& Toyota, T. in Groundwater and Subsurface Environments: Human Impacts in Asian Coastal Cities (ed. Taniguchi, M.) 249-270 (Springer, 2011); https://doi.org/10.1007/978-4-431-53904-9_13

18. Esteban, M. et al. Adaptation to sea level rise: learning from present examples of land subsidence. Ocean Coast. Manag. 189, 104852 (2020).

19. Burkett, V. B., Zilkowski, D. B. \& Hart, D. A. Sea level rise and subsidence: implications for flooding in New Orleans, Louisiana. In Proc. USGS Aquifer Mechanics and Subsidence Interest Group Conference (eds Prince, K. R. \& Galloway, D. L.) 63-70 (US Geological Survey, 2003).

20. Climate Risks and Adaptation in Asian Coastal Megacities: A Synthesis Report (World Bank, 2010)

21. Ablain, M. et al. Improved sea level record over the satellite altimetry era (1993-2010) from the Climate Change Initiative project. Ocean Sci. 11, 67-82 (2015).

22. Legeais, J. F. et al. An improved and homogeneous altimeter sea level record from the ESA Climate Change Initiative. Earth Syst. Sci. Data 10, 281-301 (2018)

23. Kriegler, E. et al. A new scenario framework for climate change research: the concept of shared climate policy assumptions. Climatic Change 122, 401-414 (2014).

24. Nicholls, R. J. et al. Stabilization of global temperature at $1.5^{\circ} \mathrm{C}$ and $2.0^{\circ} \mathrm{C}$ : implications for coastal areas. Philos. Trans R. Soc. Lond. A 376, 20160448 (2018)

25. Day, J. W. et al. Restoration of the Mississippi Delta: lessons from hurricanes Katrina and Rita. Science 315, 1679 (2007)

26. Darby, S. E., Appeaning Addo, K., Hazra, S., Rahman, M. M. \& Nicholls, R. J. in Deltas in the Anthropocene (eds Nicholls, R. J. et al.) Ch. 5 (Palgrave Macmillan, 2020); https://doi.org/10.1007/978-3-030-23517-8 5

27. Nicholls, R. J. et al. Sea-level scenarios for evaluating coastal impacts. WIREs Clim. Change 5, 129-150 (2014).

28. Erkens, G. \& Sutanudjaja, E. H. Towards a global land subsidence map. Proc. Int. Assoc. Hydrol. Sci. 372, 83-87 (2015).

29. Higgins, S. A. Review: advances in delta-subsidence research using satellite methods. Hydrogeol. J. 24, 587-600 (2016).

Publisher's note Springer Nature remains neutral with regard to jurisdictional claims in published maps and institutional affiliations.

(c) The Author(s), under exclusive licence to Springer Nature Limited 2021 


\section{Methods}

This analysis uses the framework of the Dynamic Interactive Vulnerability Assessment (DIVA) model which has been applied to problems such as coastal erosion $^{30}$, coastal flooding ${ }^{31}$ and coastal wetland change ${ }^{32}$, among others. The underlying structure is a dataset of coastal areas and floodplains based on 12,148 coastal segments which divide the world's coasts (excluding Antarctica) into lengths of similar coastal characteristics ${ }^{33}$. The segments are variable in length with an average of $70 \mathrm{~km}$. All data, such as SLR rates, socioeconomic development, extreme water levels, subsidence rates and so on, are associated with the appropriate segment.

To analyse the global effects of subsidence on relative SLR we combine data on four components of relative sea-level change:

(1) Satellite observations of sea-level change from 1993 to 2015,

(2) GIA, derived from the model of Peltier et al. ${ }^{11}$,

(3) Delta subsidence, which includes natural and anthropogenic subsidence for 117 deltas worldwide, building on the earlier work of Ericson et al. ${ }^{13}$,

(4) City subsidence, which captures the additional subsidence beyond delta subsidence that coastal cities in deltaic and alluvial plains experience. We thereby consider susceptible coastal cities with populations exceeding one million people in 2005 that are prone to subsidence (following Nicholls et al. ${ }^{34}$ ).

These four components are independent and hence can simply be summed for each segment.

We exclude uplift and subsidence due to other processes such as tectonics ${ }^{6}$ as there are no consistent global datasets available. Most analyses of these processes are local or regional (for example, ref. ${ }^{35}$ ) and obtaining the data required to create relative SLR scenarios at the global scale is problematic ${ }^{27}$. The few studies that systematically analyse data on vertical land movements globally using measurements at tide gauges ${ }^{36,37}$ find that GIA (already included in the analysis) explains a large part of the observed trends.

The major limitation in this analysis is that subsiding cities with populations of fewer than one million people are excluded, again reflecting a lack of consistent data at the global scale. This means that our estimates of the effect of city subsidence on relative SLR are minimum estimates.

For assessing the effects of future climate-induced SLR we use the same scenarios as Hinkel et al. ${ }^{31}$. For delta and city subsidence from 2015 to 2050 , we assume that the observed rates of subsidence continue at the same rate. It is recognized that these rates may be subject to considerable change, especially those due to human influence (for example, ref. ${ }^{38}$ ). Hence, they should be considered as indicative scenarios rather than projections. The purpose of the analysis is to estimate the relative magnitudes of these processes rather than create projections.

For present and future population, we use the scenarios of Merkens et al. ${ }^{39}$.

Data. The following datasets are used in this analysis.

Sea-level change. For the sea-level change observations, we use the satellite altimetry product from the European Space Agency (ESA) Climate Change Initiative (CCI) sea level project. We use this product because the data are computed with consistent geophysical corrections throughout the whole record and are thus specifically tailored for trend estimates ${ }^{21,22}$. The product is a two-dimensional gridded sea surface height of delayed time anomalies described and validated in Legeais et al..$^{22}$. We analysed the data over the period from 1993 to 2015 . The dataset is provided at monthly intervals on an $1 / 4^{\circ}$ regular grid as anomalies computed with reference to the 1993-2012 period. Sea-level anomalies for the study sites were extracted from the global dataset. At high latitude $\left(>82^{\circ}\right)$, satellite altimetry data is not available because of the inclination of the satellites. Close to the coast, data is available until $15 \mathrm{~km}$ from the coast. However, at $15 \mathrm{~km}$ from the coast some significant errors can arise in geophysical corrections applied to the sea-level estimate. These errors arise from land contamination in the satellite radiometer measurement which is used for the wet tropospheric correction, in the radar measurement which is used to estimate the altimetry range or in geophysical models such as tide models (because of inaccurate bathymetry, for example). To remove this potentially spurious data we discarded all data from less than $25 \mathrm{~km}$ from the coast. To ensure that all spurious data was removed, we checked that the difference between the data close to the coast and adjacent data offshore was within the typical sea-level variability range (following the CCI Coastal Sea Level Team ${ }^{40}$ ). For the trend estimate, we used a least-square fit that estimates the annual cycle, the semi-annual cycle and the trend at the same time. The uncertainty in the trend is estimated with an error-budget approach and is below $3 \mathrm{~mm} \mathrm{yr}^{-1}$ (at the $90 \% \mathrm{CL}$ level $\left.{ }^{21}\right)$. Note that there is some difference between the coastal sea-level trend and the sea-level trend $25 \mathrm{~km}$ offshore, but this difference does not exceed $1.5 \mathrm{~mm} \mathrm{yr}^{-1}$ ( 1 s. d.) over the satellite altimetry period (as shown by the difference between satellite altimetry and tide-gauge records corrected for vertical land motion ${ }^{41}$ or by the analysis from the CCI Coastal Sea Level Team ${ }^{40}$ ).

GIA. Local sea-level change data due to GIA caused by ice loading and unloading are taken from the ICE-6G_C (VM5a) model ${ }^{11}$. Local land movement in response to deglaciation is combined with global topography and bathymetry to compute local sea-level change on a $0.2^{\circ} \times 0.2^{\circ}$ grid. This gridded dataset is projected to the
DIVA coastal segments by assigning the average sea-level-change value over all intersected grid cells to each segment.

Delta subsidence. Delta subsidence is estimated for 117 deltas comprising the world's major deltas. For each delta, a single indicative average value is assumed (except where stated otherwise), covering a similar time period to the sea-level measurements. For 40 of the more populated deltas, data are based on those developed by Ericson et al. ${ }^{13}$, with a few corrections. These include: the GangesBrahmaputra Delta (where the value is taken from Brown and Nicholls ${ }^{42}$ ), the Mekong Delta (from Erban et al..$^{43}$ and Minderhoud et al. ${ }^{44}$ ), the North Italian Plain (from Tos et al. ${ }^{45}$ ) and the Pearl River Delta (from Wang et al. ${ }^{46}$ ). For the other 77 deltas, where there are little or no data, a minimum value of subsidence is assumed in all cases to be $1 \mathrm{~mm} \mathrm{yr}^{-1}$, following the estimates of Meckel et al. ${ }^{47}$. The delta extent is linked to the DIVA segments. Supplementary Table 1 summarizes the deltas considered and subsidence values used.

Coastal city subsidence. The set of 136 coastal cities with more than one million people in 2005 as identified by Nicholls et al. ${ }^{34}$ and Hallegatte et al. ${ }^{48}$ is considered in this analysis, along with two additional coastal cities in Indonesia which exceed the population threshold and are known to be subsiding: Semarang and Medan ${ }^{49}$. These large cities are considered in the analysis as they include the largest urban populations and the largest observed subsidence is reported in some of them as summarized in Supplementary Table 2. Of these 138 cities, 36 cities are situated wholly or partly on deltaic/alluvial deposits which may subside due to subsurface fluid withdrawal and/or drainage. In each case, the additional subsidence beyond that captured in the delta-subsidence estimates (Supplementary Table 1) is estimated based on a survey of the available literature or expert judgement if required. Given the wide range of values of subsidence reported, a low and a high estimate of average subsidence are made to represent the uncertainty. These are applied as indicative average estimates across the subsiding area in each city. These estimates of subsidence cover a similar time period to the sea-level measurements. The extent of subsidence in each city is defined by the extent of Holocene deposits which in turn is linked to the DIVA segments (that is, subsidence is not applied to the entire area of the city unless this is appropriate). These estimates are designed to represent average subsidence values across the whole subsiding area within each city. Supplementary Table 2 summarizes the coastal cites considered and the subsidence values used.

Socioeconomic scenarios. Population exposure is obtained by overlaying Shuttle Radar Topography Mission (SRTM) elevation data ${ }^{50,51}$ with Global Rural-Urban Mapping Project population data ${ }^{52}$ using resampling methods ${ }^{39}$. As coastal urbanization trends play a major role in the population exposure analysis in this study, we use five regionalized population growth projections ${ }^{39}$ based on the $S S P 2^{23,53-55}$. As the population projections do not differ much until the middle of the twenty-first century, we only report the one based on the middle-of-the-road scenario from the SSP2 in the main paper. Results for other population projections are shown in Extended Data Fig. 3. We note that other population datasets would lead to different quantitative outputs as demonstrated in the analysis of Hinkel et $\mathrm{al}^{31}$. However, the main results in the article based on population weighting are unlikely to be sensitive to these differences as the relative distribution of population along the coast is common to all global population datasets.

In terms of population statistics, we consider the population living below the $10 \mathrm{~m}$ elevation contour in 2015 for the population weighting of SLR rate, comprising 768 million people. To estimate population exposure to coastal flooding, we also consider the coastal floodplain population living below the 100 -year-flood elevation, which is dynamic in time due to relative sea-level change and population change. This population was 235 million people in 2015 .

Mean and extreme SLR scenarios to 2050. For SLR projections we use three global-mean SLR scenarios taken from Hinkel et al. ${ }^{31}$ : the 50th percentile of RCP2.6, RCP4.5 and RCP8.5 using the UK Met Office Hadley Centre Earth System Model (HadGEM-ES2) ${ }^{56}$. Extreme water levels are assumed to uniformly increase with SLR, following twentieth-century observations ${ }^{57}$. Extreme-water-level distributions are taken from the Global Tide and Surge Reanalysis (GTSR) database ${ }^{58}$ and referenced to EGM96 geoid63 (ref. ${ }^{59}$ ) to be compatible with SRTM data ${ }^{60}$.

Regional definitions utilized. The 23 global coastal regions used in this study are defined by Future Earth Coast, formerly Land Ocean Interactions in the Coastal Zone, and are similar to earlier regional definitions $s^{61,62}$. These 23 regions divide the world's coasts into geographic subsets, as defined in Supplementary Table 3.

Weighting approach. To compute global average values of the relative SLR components and their sums, the weighted average (wrslr) is computed as:

$$
\text { wrslr }=\frac{\sum_{\mathrm{cls}}(\operatorname{rslr}(\mathrm{cls}) \times w(\mathrm{cls}))}{\sum_{\mathrm{cls}} w(\mathrm{cls})}
$$

where $\mathrm{rslr}(\mathrm{cls})$ is the relative sea-level change in each coastline segment (cls) and $w(\mathrm{cls})$ is the weight per segment defined by the coastal length and coastal population per segment. 
For the length-weighted global average we set $w(\mathrm{cls})$ equal to the length of the coastline segment (cls). For the population-weighted global average we set $w(\mathrm{cls})$ equal to the population living in the low elevation coastal zone (that is, the population living within $10 \mathrm{~m}$ elevation of mean sea level ${ }^{63}$ ) in each segment in 2015. In this analysis, the global coastal length totals $691,017 \mathrm{~km}$ and the global low elevation coastal zone population is 768 million in 2015.

Coastal floodplain population. For the population in the floodplain, we consider the 100-year floodplain (using water levels from Muis et al..$^{5}$ ) based on the elevation data from the SRTM and the population scenarios mentioned above. Changes with time are evaluated per segment assuming SLR, subsidence or uplift and population change, as defined above. Coastal adaptation, including coastal defences, is not considered, and the results simply reflect the floodplain population.

Studies before Muis et al. ${ }^{60}$ did not consider the difference in vertical datum of extreme sea levels and global land elevation and thus have underestimated population exposure to flooding. While extreme-water-level datasets such as GTSR $^{60}$ use mean sea level as vertical datum, global elevation datasets such as SRTM are referenced to the EGM96 geoid $^{59}$. The offset between mean sea level and the geoid can be up to $1.5 \mathrm{~m}$, due to the dynamic sea surface of the ocean ${ }^{64}$, and is largely determined by ocean currents. Correcting the vertical datum increases the population exposed to the 100-year-flood event by $39-60 \%$ (ref. ${ }^{60}$ ).

As noted earlier, other population scenarios would lead to different quantitative estimates of coastal floodplain population ${ }^{31}$, but the relative distribution of population along the coast would be similar. Hence, it would have little influence on the weighting by population described above.

\section{Data availability}

All datasets used in the production of this paper are available from: https://doi org/10.5281/zenodo.4434773 (ref. ${ }^{65}$ ). The sea-level data are referenced under the following: https://doi.org/10.5270/esa-sea level_cci-1993 2015-v_2.0-201612. It is freely available from: http://www.esa-sealevel-cci.org/products. Source data are provided with this paper

\section{Code availability}

The $\mathrm{R}$ code used to produce the numbers, tables and figures is available from: https://doi.org/10.5281/zenodo.4434773 (ref. ${ }^{65}$ ). Source data are provided with this paper.

\section{References}

30. Hinkel, J. et al. A global analysis of erosion of sandy beaches and sea-level rise: an application of DIVA. Glob. Planet. Change 111, 150-158 (2013).

31. Hinkel, J. et al. Coastal flood damage and adaptation costs under 21 st century sea-level rise. Proc. Natl Acad. Sci. USA 111, 3292-3297 (2014).

32. Schuerch, M. et al. Future response of global coastal wetlands to sea-level rise. Nature 561, 231-234 (2018).

33. Vafeidis, A. T. et al. A new global coastal database for impact and vulnerability analysis to sea-level rise. J. Coast. Res. 24, 917-924 (2008).

34. Nicholls, R. J. et al. Ranking Port Cities with High Exposure and Vulnerability to Climate Extremes-Exposure Estimates OECD Environment Working Papers No. 1 (OECD Publishing, 2008); https://doi.org/10.1787/011766488208

35. National Research Council. Sea-level Rise for the Coasts of California, Oregon, and Washington: Past, Present, and Future (National Academies Press, 2012).

36. Ostanciaux, E., Husson, L., Choblet, G., Robin, C. \& Pedoja, K. Present-day trends of vertical ground motion along the coast lines. Earth Sci. Rev. 110, 75-92 (2012).

37. Pfeffer, J. \& Allemand, P. The key role of vertical land motions in coastal sea level variations: a global synthesis of multisatellite altimetry, tide gauge data and GPS measurements. Earth Planet. Sci. Lett. 439, 39-47 (2016).

38. Phien-wej, N., Giao, P. H. \& Nutalaya, P. Land subsidence in Bangkok, Thailand. Eng. Geol. 82, 187-201 (2006).

39. Merkens, J.-L., Lincke, D., Hinkel, J., Brown, S. \& Vafeidis, A. T. Regionalisation of population growth projections in coastal exposure analysis. Climatic Change 151, 413-426 (2018).

40. The Climate Change Initiative Coastal Sea Level Team Coastal sea level anomalies and associated trends from Jason satellite altimetry over 2002-2018. Sci. Data https://doi.org/10.1038/s41597-020-00694-w (2020).

41. Wöppelmann, G. \& Marcos, M. Vertical land motion as a key to understanding sea level change and variability. Rev. Geophys. 54, 64-92 (2016).

42. Brown, S. \& Nicholls, R. J. Subsidence and human influences in mega deltas: the case of the Ganges-Brahmaputra-Meghna. Sci. Total Environ. 527-528, 362-374 (2015).

43. Erban, L. E., Gorelick, S. M. \& Zebker, H. A. Groundwater extraction, land subsidence, and sea-level rise in the Mekong Delta, Vietnam. Environ. Res. Lett. 9, 084010 (2014).

44. Minderhoud, P. S. J. et al. Impacts of 25 years of groundwater extraction on subsidence in the Mekong Delta, Vietnam. Environ. Res. Lett. 12, 064006 (2017)
45. Tos, L., Da Lio, C., Strozzi, T. \& Teatini, P. Combining L- and X-Band SAR interferometry to assess ground displacements in heterogeneous coastal environments: the Po River Delta and Venice Lagoon, Italy. Remote Sens. 8, 308 (2016).

46. Wang, H. et al. InSAR reveals coastal subsidence in the Pearl River Delta, China. Geophys. J. Int. 191, 1119-1128 (2012).

47. Meckel, T. A., ten Brink, U. S. \& Williams, S. J. Sediment compaction rates and subsidence in deltaic plains: numerical constraints and stratigraphic influences. Basin Res. 19, 19-31 (2007).

48. Hallegatte, S., Green, C., Nicholls, R. J. \& Corfee-Morlot, J. Future flood losses in major coastal cities. Nat. Clim. Change 3, 802-806 (2013).

49. Chaussard, E., Amelung, F., Abidin, H. \& Hong, S.-H. Sinking cities in Indonesia: ALOS PALSAR detects rapid subsidence due to groundwater and gas extraction. Remote Sens. Environ. 128, 150-161 (2013).

50. Rabus, B., Eineder, M., Roth, A. \& Bamler, R. The shuttle radar topography mission-a new class of digital elevation models acquired by spaceborne radar. ISPRS J. Photogramm. Remote Sens. 57, 241-262 (2003).

51. Jarvis, A., Reuter, H. I., Nelson, A. \& Guevara, E. Hole-Filled SRTM for the Globe Version 4 (CGIAR Consortium for Spatial Information, 2008); http:// srtm.csi.cgiar.org

52. Center for International Earth Science Information Network Columbia University, International Food Policy Research Institute, World Bank \& Centro Internacional de Agricultura Tropical Global Rural-Urban Mapping Project, Version 1 (GRUMPv1): Population Count Grid (NASA Socioeconomic Data and Applications Center, 2011); https://doi.org/10.7927/H4VT1Q1H

53. IIASA. SSP Database (2012); https://tntcat.iiasa.ac.at/SspDb

54. O’Neill, B. C. et al. A new scenario framework for climate change research: the concept of shared socioeconomic pathways. Climatic Change 122, 387-400 (2014).

55. Samir, K. C. \& Lutz, W. The human core of the shared socioeconomic pathways: population scenarios by age, sex and level of education for all countries to 2100. Glob. Environ. Change 42, 181-192 (2017).

56. Collins, W. J. et al. Development and evaluation of an Earth-System Model-HadGEM2. Geosci. Model Dev. 4, 1051-1075 (2011).

57. Menéndez, M. \& Woodworth, P. L. Changes in extreme high water levels based on a quasi-global tide-gauge data set. J. Geophys. Res. Oceans https:// doi.org/10.1029/2009JC005997 (2010).

58. Muis, S., Verlaan, M., Winsemius, H. C., Aerts, J. C. J. H. \& Ward, P. J. A global reanalysis of storm surges and extreme sea levels. Nat. Commun. 7, 11969 (2016).

59. Farr, T. G. et al. The shuttle radar topography mission. Rev. Geophys. https:// doi.org/10.1029/2005RG000183 (2007).

60. Muis, S. et al. A comparison of two global datasets of extreme sea levels and resulting flood exposure. Earths Future 5, 379-392 (2017).

61. Hoozemans, F. M. J., Marchand, M. \& Pennekamp, H. A. Sea Level Rise: A Global Vulnerability Analysis: Vulnerability Assessment for Population, Coastal Wetlands and Rice Production on a Global Scale (Deltares, 1993); https:// repository.tudelft.nl/islandora/object/ uuid:651e894a-9ac6-49bf-b4ca-9aedef51546f

62. Nicholls, R. J. \& Hoozemans, F. M. J. in Encyclopedia of Coastal Science (ed. Schwartz, M. L.) 486-491 (Springer Netherlands, 2005); https://doi. org/10.1007/1-4020-3880-1_155

63. McGranahan, G., Balk, D. \& Anderson, B. The rising tide: assessing the risks of climate change and human settlements in low elevation coastal zones. Environ. Urban. 19, 17-37 (2007).

64. Schaeffer, M., Hare, W., Rahmstorf, S. \& Vermeer, M. Long-term sealevel rise implied by $1.5^{\circ} \mathrm{C}$ and $2^{\circ} \mathrm{C}$ warming levels. Nat. Clim. Change 2, 867-870 (2012)

65. Nicholls, R. J. et al. A global analysis of subsidence, relative sea-level change and coastal flood exposure. zenodo https://doi.org/10.5281/zenodo.4434773 (2021).

\section{Acknowledgements}

We thank J. Ericson for sharing his dataset on delta subsidence. R.J.N. was supported under the Deltas, Vulnerability and Climate Change: Migration and Adaptation project (International Development Research Centre (IDRC), Canada, 107642) under the Collaborative Adaptation Research Initiative in Africa and Asia programme with financial support from the UK Government's Department for International Development, the IDRC, Canada and the PROTECT Project. The views expressed in this work are those of the creators and do not necessarily represent those of the Department for International Development and IDRC or their boards of governors We thank the ESA CCI sea level project for providing the level 4 sea-level data and Centre National d'Etudes Spatiales (CNES) for providing the level 2 data from the Topex and Jason 1, 2 and 3 satellites. Other portions of this research were made possible by support from the European Union through the projects Responses to coastal climate change: Innovative Strategies for high End Scenarios - Adaptation and Mitigation (RISES-AM) funded by the European Commission's Seventh Framework Programme, 2007-2013, under the grant agreement number 603396), and Green growth and win-win strategies for sustainable climate action (GREEN-WIN) and 
CO-designing the Assessment of Climate CHange costs (COACCH), both of which are funded by European Union's Horizon 2020 research and innovation programme under grant agreement numbers 642018 and 776479, respectively. Further funding was received through two projects, INSeaPTION and ISIpedia, which are part of European Research Area for Climate Services (ERA4CS), an ERA-NET initiative by JPI Climate, and funded by the Research Council for Sustainable Development (Formas), Sweden; Federal Ministry of Education and Research (BMBF), Germany (grant numbers 01LS1711C and 01LS1703A); Federal Ministry of Science, Research and Economy (BMWFW), Austria; Innovation Fund Denmark (IFD); Ministry of Economic Affairs and Digital Transformation (MINECO), Spain; and National Research Agency (ANR), France, with co-funding by the European Union (grant 690462). This publication was supported by PROTECT. This project has received funding from the European Union's Horizon 2020 research and innovation programme under grant agreement number 869304, PROTECT contribution number 8 .

\section{Author contributions}

R.J.N., D.L. and J.H. designed and conducted the analysis and wrote the main paper. They also prepared the city-subsidence and glacial-isostatic-adjustment data. S.B. and S.E.H. contributed to the city-subsidence data and prepared the data on delta subsidence.
A.T.V. and J.-L.M. prepared the socioeconomic data. B.M. provided the satellite sea-level data and the expertise on climate-induced coastal sea-level rise. J.F. contributed to the city-subsidence data from Asia, especially China. All authors read paper drafts and approved the final version.

\section{Competing interests}

The authors declare no competing interests.

\section{Additional information}

Extended data is available for this paper at https://doi.org/10.1038/s41558-021-00993-z.

Supplementary information The online version contains supplementary material available at https://doi.org/10.1038/s41558-021-00993-z.

Correspondence and requests for materials should be addressed to R.J.N.

Peer review information Nature Climate Change thanks Devin Galloway, Nobuo Mimura and the other, anonymous, reviewer(s) for their contribution to the peer review of this work.

Reprints and permissions information is available at www.nature.com/reprints. 


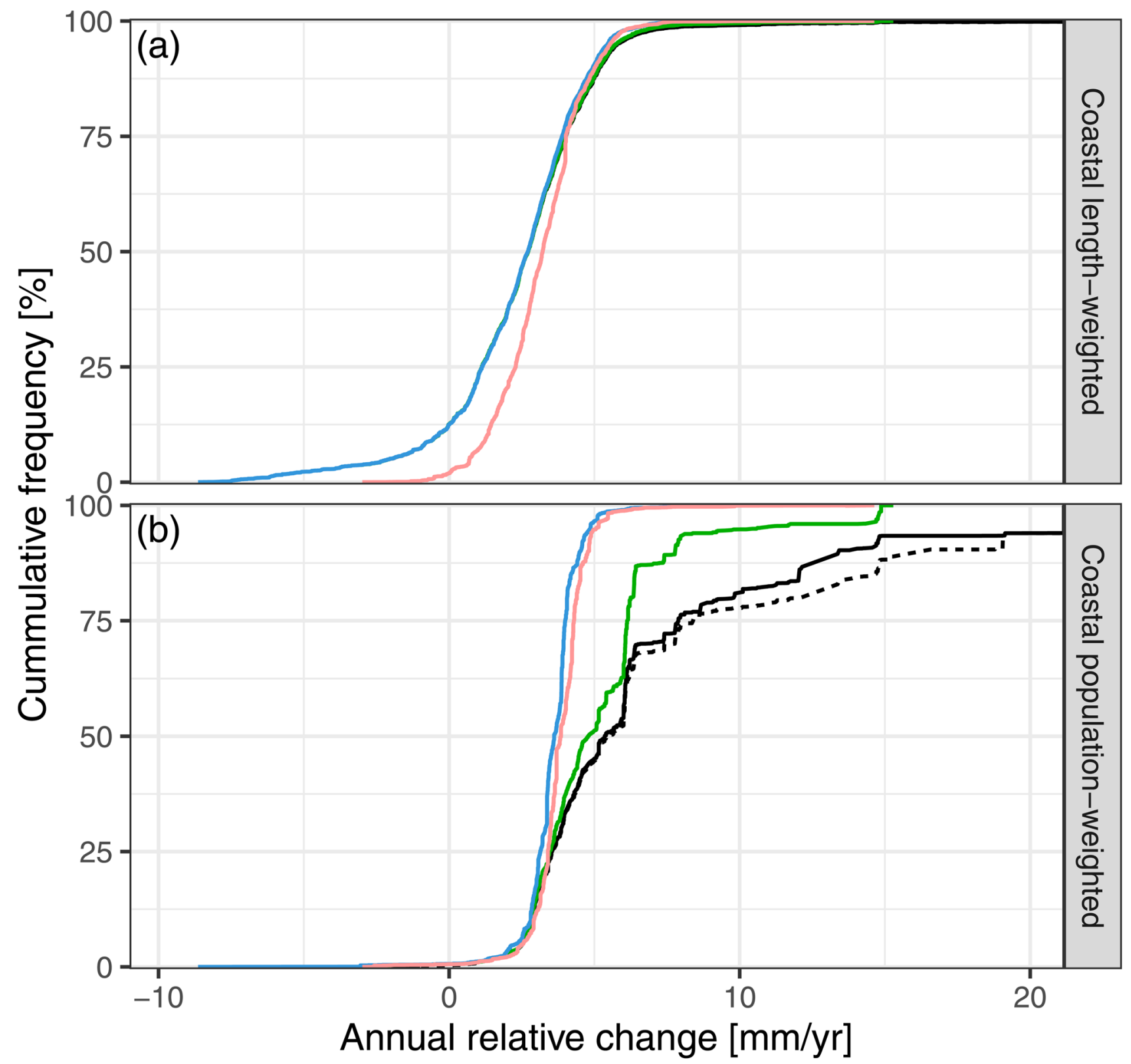

- lower estimate -- upper estimate

\section{Climate Induced SLR}

\section{Climate Induced SLR + GIA + Delta}

Climate Induced SLR + GIA

\section{Climate Induced SLR + GIA + Delta + Ci}

Extended Data Fig. 1 | Cumulative distribution of contemporary coastal relative SLR. (a) length-weighted, (b) population-weighted. Each panel shows climate-induced SLR alone, and then progressively adds the other components comprising: (1) GIA, (2) GIA and delta subsidence combined, and (3) GIA, delta subsidence and uncontrolled city subsidence combined. For uncontrolled city subsidence, the uncertainty is considered by using a low and high estimate. For length weighting, the main change occurs due to adding the GIA component, which reduces the median and mean SLR. Considering delta and city subsidence has little effect as only 6.5 percent and 0.8 percent of the world's coast length are affected. For population weightings, adding GIA also has an effect, but it is smaller than for length weighting being $-0.3 \mathrm{~mm} / \mathrm{yr}$ on mean SLR. This reflects that the coastal population is preferentially located in areas where GIA causes subsidence, which counters the effect GIA has when considering length weighting. Adding delta and then uncontrolled city subsidence has a major effect reflecting the large populations in these areas. In the median, these two components add $1.19 \mathrm{~mm} / \mathrm{yr}$ and an additional $0.62 \mathrm{~mm} / \mathrm{yr}$ of SLR rise, respectively. The asymmetric distribution of the high-end tail leads to a larger effect on the mean SLR at $1.6 \mathrm{~mm} / \mathrm{yr}$ due to delta subsidence alone, and an additional 2.7 to $4.8 \mathrm{~mm} / \mathrm{yr}$ due to city subsidence alone (Table 1). 

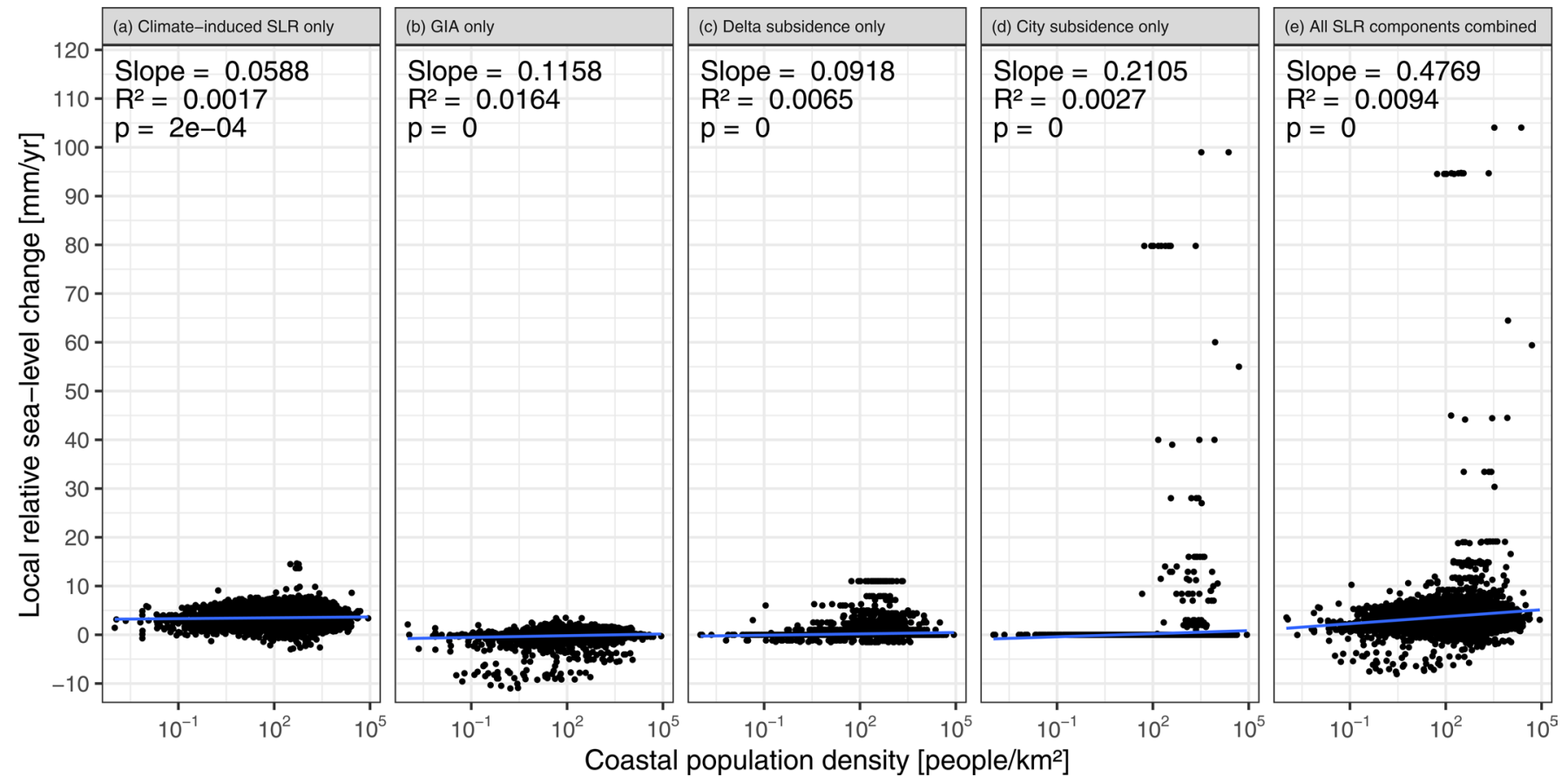

Extended Data Fig. 2 | Sea-level rise components versus coastal population density for all the coastal segments considered in the analysis. These comprise (a) climate-induced sea-level rise only, (b) GIA only, (c) high estimates of uncontrolled city subsidence only, (d) delta subsidence only, and (e) the sum of all four components considered previously. The linear best fit and the explained variance are shown in each case. While the explained variance with such a linear fit is small, the slopes are significantly different from zero in all cases. 


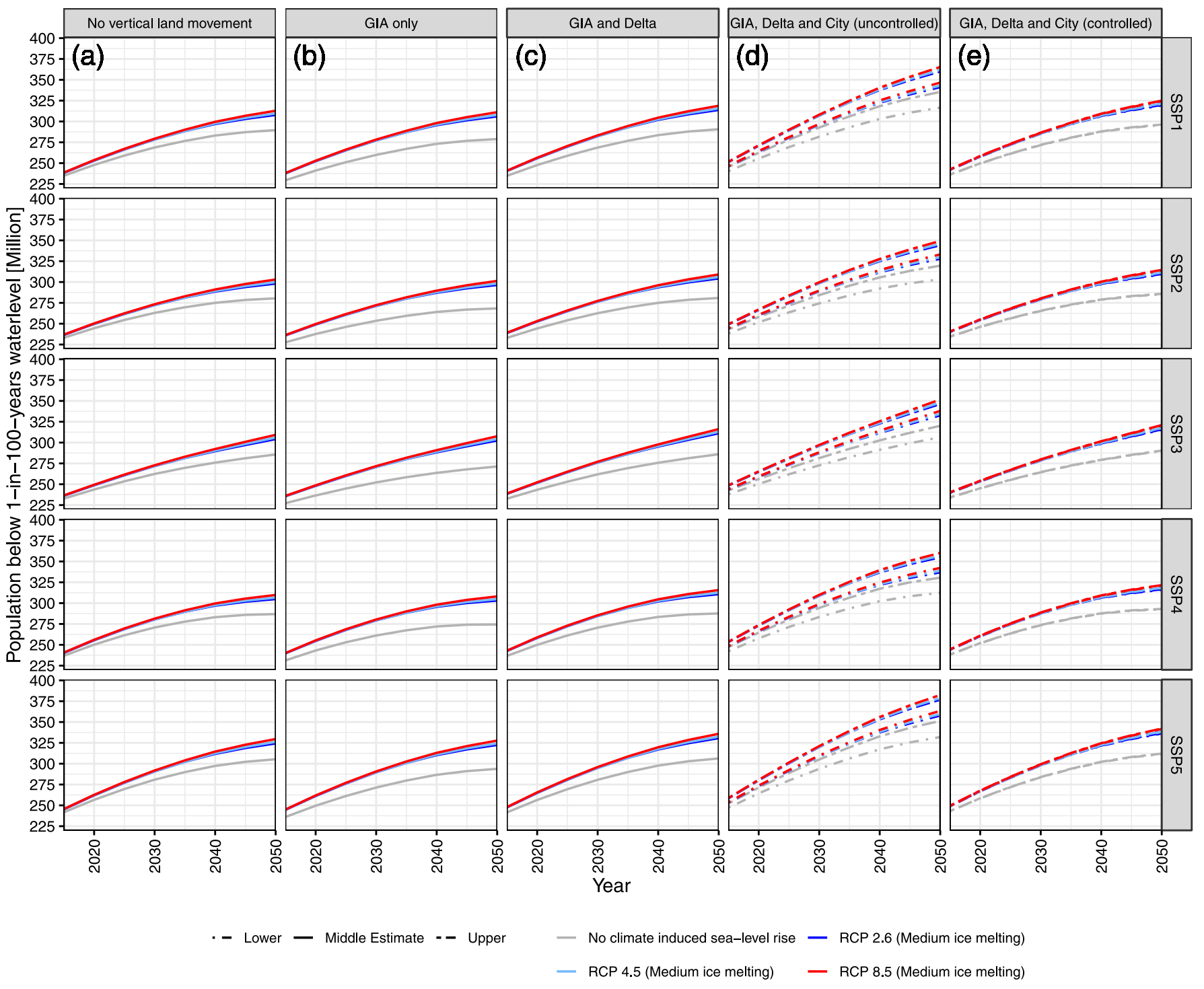

Extended Data Fig. 3 | Global total of people living in the coastal flood plain from 2015 to 2050 under a range of socio-economic and climate scenarios. These comprise five different SSP-based regionalised population scenarios (SSP1 to SSP5), and no climate-induced SLR and the RCP2.6 and RCP8.5 SLR scenarios, respectively. Assumptions concerning geological components of relative SLR are as follows: Column (a) No geological component, Column (b) GIA only, Column (c) GIA and delta subsidence, Column (d) GIA, delta and uncontrolled city subsidence. Column (e) GIA, delta and controlled city subsidence (to a maximum of $5 \mathrm{~mm} / \mathrm{yr}$ ). The lower, middle and upper population estimates in (d) and (e) reflect uncertainty in the rates of city subsidence (see Fig. 1). All simulations start in 1995. The results indicate little variation between SSPs to 2050. 